\title{
Significado do Tempo Livre para Adolescentes de Classe Popular
}

Meaning of free-time for popular class adolescents

Jorge Castellá Sarriera, Ângela Carina Paradiso, Paula Nunes Mousquer,

Luciana Fernandes Marques,

Júlia Schneider Hermel \& Roberta P. Schell Coelho

Universidade Federal do Rio Grande do Sul

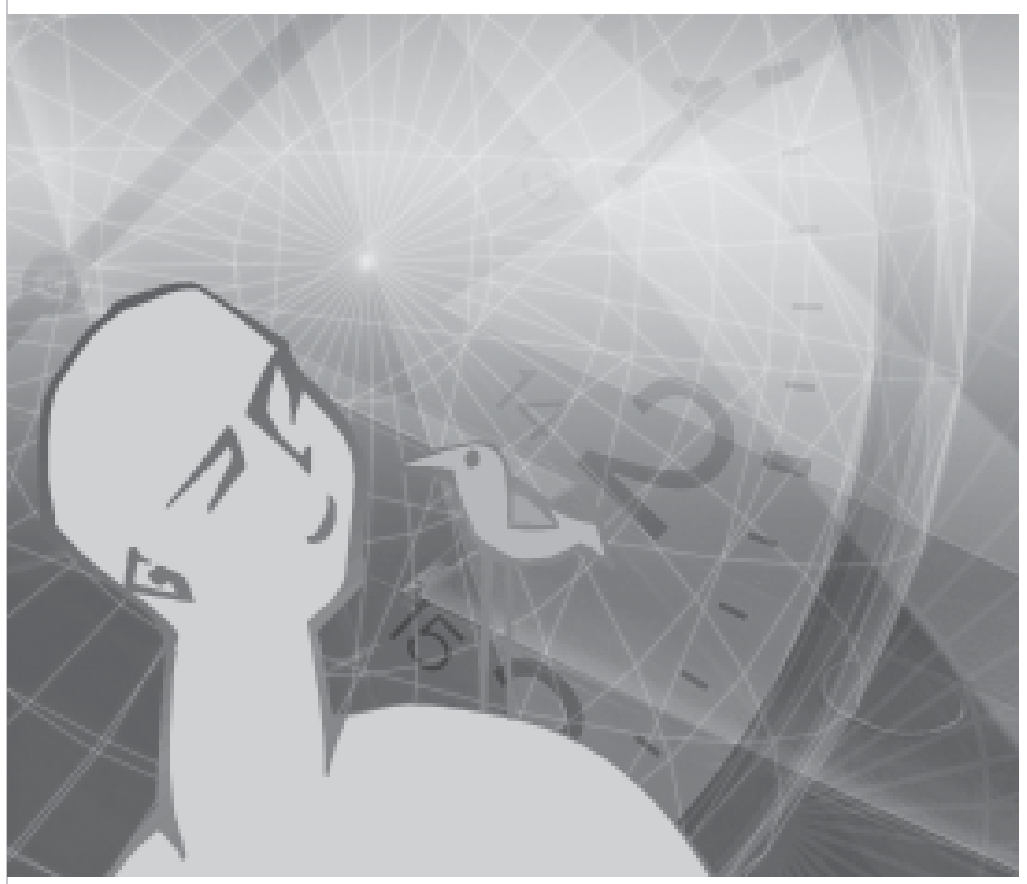




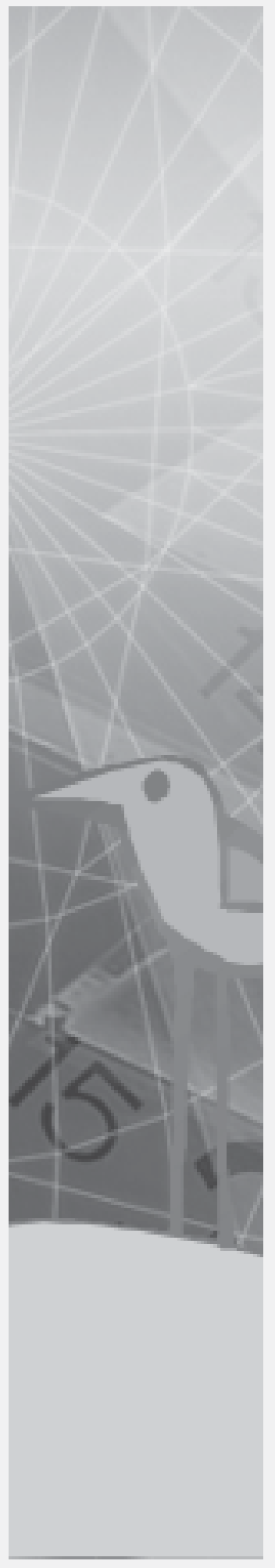

Resumo: O presente artigo é uma pesquisa descritiva de cunho qualitativo sobre os significados que adolescentes de classe popular atribuem ao tempo livre. Participaram da pesquisa 120 adolescentes escolarizados de ambos os sexos, entre 12 e 18 anos, de Porto Alegre (RS - Brasil). Os resultados colhidos através de 15 grupos focais identificaram a dissonância entre as crenças e os conhecimentos sobre o tempo livre e as práticas dos adolescentes assim como os diversos sentidos atribuídos às mesmas atividades em termos de liberdade e prazer. Os significados estão unidos às experiências dos participantes e sua complexidade depende das contingências contextuais, e estão permeados pelas interligações entre diferentes conceitos emergidos. Observamos diferenças entre os grupos etários em relação à percepção de liberdade de escolha no tempo livre. Às vezes, o ócio objetiva desenvolvimento, e é um período produtivo no qual há investimentos no âmbito social, cultural ou pessoal. Por vezes, há também uma percepção do ócio como descanso, na medida em que relacionam tempo livre com idéias de compensação do cansaço oriundo das tarefas cotidianas. Observamos diferenças entre os grupos etários em relação à percepção de liberdade de escolha no tempo livre.

Palavras-chave: tempo livre, adolescência, ócio, lazer, classe popular, escola pública, prevenção, comportamento de risco.

Abstract: This article is a descriptive research with qualitative character about the meanings that low-class teenagers give to leisure time. 120 teenager students (male and female), between 12 and 18 years old, who live in Porto Alegre (RS - Brazil), took part in the research. The final results of the 15 focal groups identified incongruences in the beliefs and knowledge about leisure time and about the teenager's activities, as well as in the different senses attributed to the same activities in terms of freedom and pleasure. The meanings are related to the participant's experiences and their complexity depends on contextual contingencies, being permeated by the concepts' interconexions brought up by the teenagers. We observed differences on the perception of leisure time freedom of choice among the age groups. Leisure time may be a means of development, a productive period in which there are investments in social, cultural and personal context. There's also a perception of leisure time as a compensation for work. The usage of leisure time has a fundamental function in the healthy development and it can only be analized and understood based on the meaning that the teenager has given to it.

Key words: leisure time, adolescence, low-class, public school, prevention, risk behavior. 
O tempo livre pode ser compreendido como um espaço temporal no qual o indivíduo pode dar vazão às suas expectativas, realizar determinadas atividades e não outras, e estas podem se refletir em desenvolvimento pessoal, integração social, descoberta da criatividade e individualidade

Codina; Zamora, R.; Toledo, M.; Santi, P. , Martinez,
O tempo livre pode ser compreendido como um espaço temporal no qual o indivíduo pode dar vazão às suas expectativas, realizar determinadas atividades e não outras, e estas podem se refletir em desenvolvimento pessoal, integração social, descoberta da criatividade e individualidade (Codina, 2002; Zamora, R.; Toledo, M.; Santi, P. , Martinez, M., 1995). As vivências culturais, os hábitos adquiridos e os processos de socialização refletem-se no uso do tempo livre e este, reciprocamente, se expressa a partir de tais variáveis sociais. Assim, a maneira como o indivíduo desfruta o tempo livre se relaciona com a conjuntura social, cultural, econômica, ideológica e física na qual está inserido (Cunha, 1987) e inclui variáveis psicológicas individuais.

O uso do tempo livre por jovens tem sido associado tanto a estímulos de autodesenvolvimento quanto a violência e condutas de risco (Castro e Abramovay, 2003). Entende-se como fatores de risco eventos de vida que, quando presentes, aumentam a probabilidade de o indivíduo apresentar problemas físicos, psicológicos e sociais. Já os fatores de proteção se referem às influências que modificam, melhoram ou alteram respostas pessoais a determinados riscos de desadaptação (Assis, Pesce e Avanci, 2006).

Os adolescentes vivenciam uma fase em que estão mais expostos a novas e atraentes experiências, e estas podem afetar sua saúde e segurança seja promovendo a qualidade de vida, seja colocando-os em risco. É comum a exposição a atividades relacionadas à sexualidade, uso de drogas e álcool, violência e acidentes de trânsito (Câmara, 2003; Gorayeb, 1990).

As informações fornecidas sobre os riscos para a saúde não parecem ser efetivas para que o jovem os evite. Segundo Câmara (2003), o que poderá definir a tomada de decisão do jovem em relação a condutas de risco ou proteção será a conjunção das informações obtidas por diversos meios e a observação do comportamento do grupo de iguais, tanto mais influente quanto mais próximo, uma vez que os valores estão ligados ao compartilhamento das novas experiências.

Em função dessas características da faixa etária e do contexto brasileiro em que o jovem está inserido, propomos descrever qualitativamente os significados que adolescentes de classe popular atribuem ao tempo livre. Dessa forma, pretendemos entender melhor o papel desse tempo “de liberdade” como fator de proteção ou risco segundo a perspectiva adolescente. Além disso, este trabalho pretendeu alinharse às diretrizes de políticas públicas já em andamento, como o Estatuto da Criança e do Adolescente (ECA) e à recomendação da OPAS (Organização Pan-Americana da Saúde) de atender a saúde dos adolescentes com programas de pesquisa, intervenção e avaliação (Tanaka, 2001).

A fim de compreender a relação entre tempo livre e a realização de atividades que promovam saúde e/ou possam desencadear comportamentos de risco, deve-se analisar a percepção e a avaliação que o indivíduo faz em relação à realidade da qual participa, de suas interações e dos recursos comunitários disponíveis (Argyle, 1993; Fernández, Martín e Muñoz, 1993). A partir de suas escolhas e de como percebe o tempo livre, o adolescente pode incrementar seu desenvolvimento pessoal e aumentar o bem-estar psicológico ou tornar-se mais vulnerável a comportamentos de risco.

Embora o estudo dos comportamentos de risco não seja o foco principal deste trabalho, entendemos que, dependendo do significado e do uso do tempo livre pelos adolescentes, 
este estudo pode influenciar o seu desenvolvimento saudável e prevenir condutas que o coloquem em risco.

Codina (2002) sinaliza que estudos da área do ócio e do tempo livre estão voltando-se cada vez mais para a relação ócio-self. O interesse de tais investigações está na compreensão de como as atividades humanas que dizem respeito ao ócio afetam diferentes dimensões ou componentes do sistema de self. Em outras palavras, preocupa-se em conhecer e compreender em que medida o ócio contribui para o desenvolvimento do self.

Inversamente, pode-se investigar como o desejo ou necessidade de auto-realização pode incidir sobre o ócio. Ao usufruir o tempo livre enquanto tempo de ócio, o indivíduo pode expandir a capacidade de auto-realização, autoestima, autoconceito e auto-imagem (Codina, 1999, 2002, 2004). Com isso, enfatiza-se a perspectiva do sujeito como alguém que potencialmente se pensa, se vê, se sente e se satisfaz através do seu comportamento durante o tempo livre.

Codina (2002) destaca que as dimensões e variáveis pelas quais se pode analisar o ócio são: a dimensão temporal e a de liberdade. $\mathrm{Na}$ dimensão temporal, pode-se analisar a quantidade de tempo que as pessoas dedicam ao ócio, como distribuem esse tempo ao longo do dia, da semana ou do ano (como, por exemplo, finais de semana ou férias).

No que se refere à dimensão de liberdade, esta pode ser analisada através do seu conteúdo, como o desenvolvimento, o descanso, a diversão (Dumazedier, 1973) ou outras satisfações, ou ainda no que se refere aos comportamentos de escolha e realização do ócio. Munné (1985) propõe que o ócio funcione como um tempo liberador, ou seja, um tempo liberado de algo. Esse autor diferencia a liberdade no tempo livre e a liberdade do tempo livre, ou seja, primeiro é preciso estar liberado de para então ser livre para.

As atividades de ócio, então, correspondem a um comportamento pautado pela liberdade quando são realizadas como um fim em si mesmas, e não mais motivadas por necessidades compensatórias. Em outras palavras, quanto mais liberado é o tempo da necessidade de compensação, mais livre ele será (Munné; Codina, 1996; 2002).

A liberdade, tida como um valor e um direito humano por excelência, constitui um dos elementos centrais para a compreensão do ócio enquanto fenômeno psicossocial (Casas; Codina, 1998). Sendo assim, as atividades de ócio enquanto tempo livre devem refletir um comportamento autocondicionado. (Munné; Codina,1996).Enquanto o autocondicionamento é compreendido como um condicionamento pela liberdade, o heterocondicionamento diz respeito ao condicionamento por obrigação ou necessidade (Casas; Codina, 1998; Munné, 1985, citado por Codina, 2004, p. 338).

A percepção de condicionamento no comportamento, entretanto, não é simples de ser compreendida. Em seus estudos sobre o self e o comportamento no tempo livre, Codina (2004) tem observado a manifestação de aspectos “borrosos”, e busca compreendê-los através do paradigma da complexidade. A lógica da "borrosidade" significa uma lógica da ambigüidade, e não uma lógica ambígüa. Impreciso, vago, "borroso” é o objeto que se estuda, e não a lógica em si, conforme explica a autora em um trabalho sobre a complexidade do self e a "borrosidade" (Codina, 2004). De acordo com a realidade empírica investigada pela autora, a percepção de liberdade ou obrigatoriedade no que diz respeito ao 
condicionamento do comportamento no tempo livre não é oposta. Além disso, uma mesma atividade recebe diferentes atribuições ao longo do tempo e em distintas situações, ou seja, nem sempre a percepção de liberdade se correlaciona com a percepção de tempo livre.

A temática do tempo livre se presta a uma análise complexa que contenha esses múltiplos elementos. A complexidade, segundo Battram (1999), é um enfoque epistemológico que compreende os fenômenos de forma circular, caracterizando os sistemas adaptativos numa condição de universo integrado, rico e variado. O paradigma da complexidade enfatiza que nada está realmente isolado no universo, mas sim, em contínua relação. Podemos diferenciar uma parte, mas não separá-la do todo. A parte está no todo, como o todo está na parte. Dessa forma, o indivíduo reflete e é reflexo do contexto social: influencia o meio e é influenciado por este.

O pensamento complexo não é completo, mas um pensamento no qual predomina a incerteza, no qual nenhuma possibilidade é descartada (Schnitman, 1995). Conforme Morin (1996), para pensarmos complexamente, precisamos abrir mão das certezas que levam a um conhecimento absoluto e das linearidades que nos dão uma falsa noção de segurança e de respostas finais. A incerteza também se mostra presente pelo interesse do investigador nas interações que se estabelecem entre as variáveis em estudo, e não nas entidades em si mesmas.

O sistema indivíduo-relações-natureza não pode ser explicado por um número finito de variáveis, mas apenas no seu contexto, nos seus antecedentes históricos, na sua intersubjetividade. O social não é aqui considerado uma realidade natural e auto- evidente, mas uma realidade construída a partir de pontos de vista e que também pode ser desconstruída, interrogada e questionada (Schnitman, 1995).

O tempo livre, neste estudo, é compreendido como um fenômeno dinâmico e não linear. Sustentando-se, então, no paradigma da complexidade, objetivamos compreender o significado que os adolescentes de classe popular atribuem ao tempo livre.

\section{Método}

$\mathrm{Na}$ pesquisa, de abordagem qualitativa, participaram 120 adolescentes de ambos os sexos, com idade entre 12 e 18 anos, estudantes de escolas públicas de Porto AlegreRS, classificadas como de classe popular por características de localização na periferia e pela insuficiência de recursos. As escolas foram escolhidas sistematicamente através de uma lista, fornecida pelas Secretárias de Educação Estadual e Municipal, que continha os nomes das escolas estaduais e municipais localizadas em zonas periféricas. Após o consentimento da s Secretarias de Educação, 15 escolas foram contatadas pelos pesquisadores para agendar a coleta de dados. No total, foram realizados 15 grupos focais, sendo 8 com adolescentes de 12 a 14 anos e 7 com adolescentes de 15 a 18 anos. Para a análise dos dados, as verbalizações emergidas nos grupos focais foram gravadas e transcritas.

\section{Resultados}

Mediante a análise das verbalizações, elaboramos, para fins didáticos, uma matriz compreensiva que contém os diferentes e nãoexcludentes significados acerca do tempo livre. Em cada categoria - tempo de liberdade, tempo de prazer e tempo de ócio - os significados foram agrupados em subcategorias que abrangem percepções mais específicas a respeito do tempo livre, como apresentada na figura 1. 


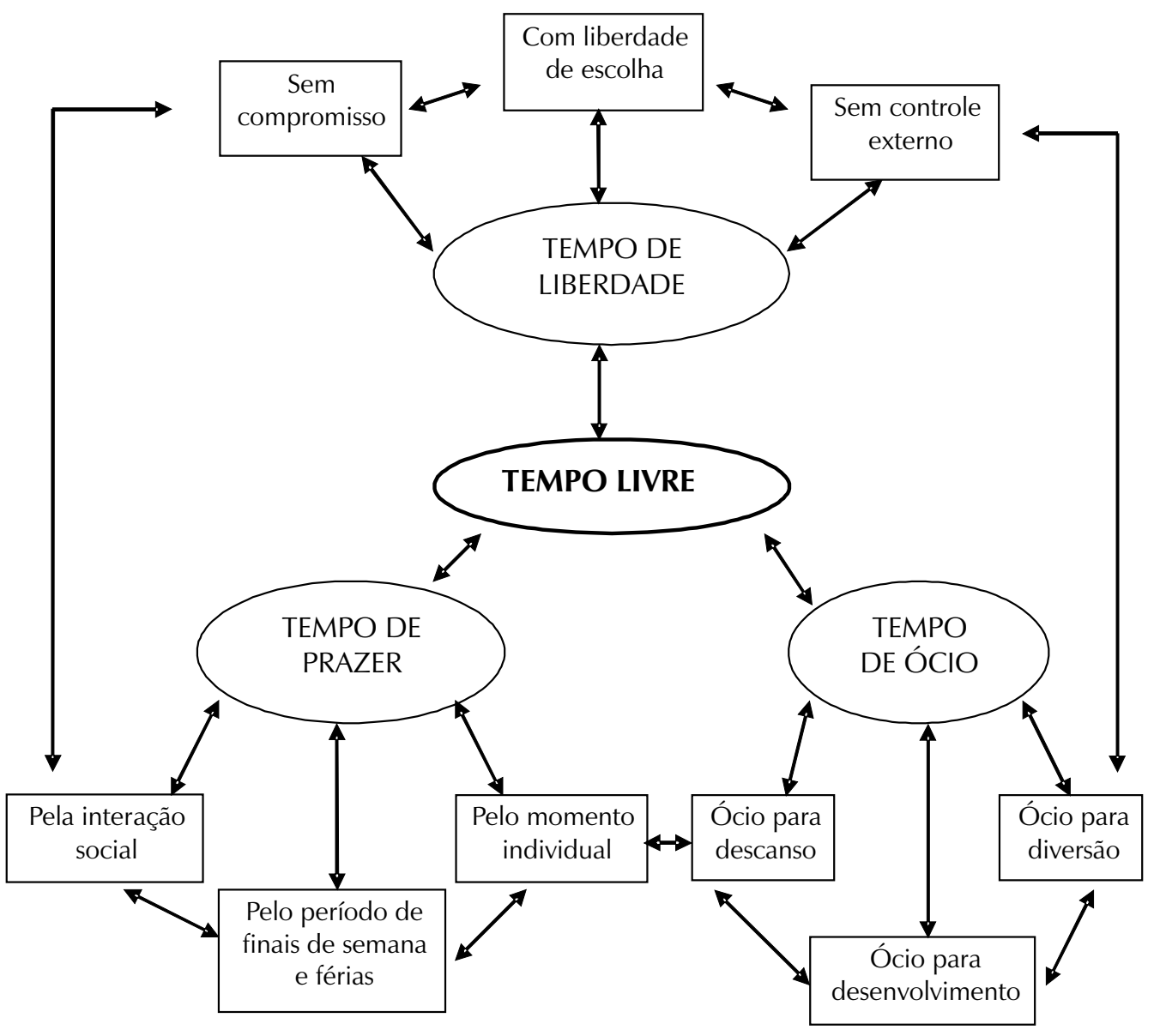

Figura 1: Signifcados do tempo livre.

A percepção de liberdade no tempo livre dos adolescentes está atrelada à noção de um tempo em que não há compromisso e, portanto, obrigação com a realização de determinada atividade: " $E$ quando não tem obrigação de fazer nada com ninguém.” (E10 - grupo 15 a 18 anos). A falta desse comprometimento com algo ou alguém leva o adolescente a também interpretar esse tempo como um momento no qual pode livremente escolher o que deseja fazer: "É um tempo para eu fazer o que eu escolher" (E7 - grupo 12 a 14 anos). O tempo livre, compreendido a partir da autonomia do adolescente, é ainda significado pela ausência de controle do meio externo sobre a ação no tempo livre: "É a única hora que ninguém manda em mim.” (E3 - grupo 12 a 14 anos).

Observamos diferenças entre os grupos etários em relação à percepção de liberdade de escolha no tempo livre visto que no grupo de 12 a 14 anos, existe maior controle do meio externo, o que reduz a possibilidade de autonomia desses adolescentes. Embora esse grupo etário tenha apresentado maior disponibilidade de tempo, não possuía autonomia suficiente para optar livremente por atividades de lazer devido à dependência da família e às restrições sociais e culturais. Percebemos, ainda, que esses adolescentes estão mais atrelados ao consentimento dos familiares (mais heterocondicionados) do que o grupo de 15 a 18 anos no que diz respeito às atividades do uso do tempo livre, tais como ir a festas, namorar e distanciar-se do âmbito doméstico sozinhos. No grupo de adolescentes mais velhos, constatamos a gradativa conquista de um espaço de maior liberdade, no qual há um menor condicionamento de familiares e/ou instituições sobre o tempo livre. 
Além de o tempo livre ter sido significado a partir da liberdade de escolha, percebemoso quanto as idéias de satisfação e prazer estão atreladas à noção de tempo livre.
Além de o tempo livre ter sido significado a partir da liberdade de escolha, percebemos o quanto as idéias de satisfação e prazer estão atreladas à noção de tempo livre. Dessa forma, os adolescentes relatam que no tempo livre “fazem o que gostam”, ou seja, realizam atividades que lhes proporcionam prazer. A obtenção de satisfação está relacionada tanto a momentos de interação desses adolescentes com amigos e/ou familiares quanto a situações nas quais realizam atividades de forma individual. Assim, quando os adolescentes enunciam: "Me encontro com os amigos, a gente fica conversando, falando bobagem, ouvindo música, jogando computador" (E6 - grupo 12 a 14 anos) e "Gosto de ficar em casa, escutando rádio, músicas meio antigas” (E6- grupo 15 a 18 anos), estão subsidiando a impressão de tempo de prazer de forma coletiva e individual, respectivamente.

Também foi possível observar que as atividades consideradas prazerosas pelos adolescentes estão, muitas vezes, direcionadas a períodos específicos, como finais de semana e férias. " $E$ que como no final de semana é quando tu tem o tempo livre mais legal, então tu tem que aproveitar, tenta aproveitar o máximo" (E12grupo de 15 a 18), ou seja, certas atividades de tempo livre são vivenciadas como momentos de muita satisfação, uma vez que os adolescentes dispõem de maior liberdade de tempo e também de autonomia para escolher suas atividades, e assim aproveitá-las ao máximo.

Os participantes da pesquisa ainda interpretaram o tempo livre como um tempo de ócio. De acordo com as verbalizações dos participantes, podemos distinguir o tempo de ócio a partir de três perspectivas: ócio para desenvolvimento, ócio para diversão e ócio para descanso.

$\mathrm{Na}$ dimensão do ócio que objetiva desenvolvimento, os adolescentes trazem idéias que se referem ao tempo livre como um período produtivo no qual há investimentos no âmbito social, cultural ou pessoal: "Segunda e quarta a gente faz grupo de estudos". (E5 - grupo 15 a 18 anos). O ócio para diversão contempla a percepção dos adolescentes que atribuem ao tempo livre o significado de criação e distração. Isso pode ser observado numa fala de um adolescente do grupo de 15 a 18 anos: "Tempo livre pra mim é lazer. Sair, jogar uma bola.” (E9 - grupo 15 a 18 anos).

Já o tempo de ócio sentido como descanso está presente na medida em que relacionam tempo livre com idéias de compensação do cansaço oriundo das tarefas cotidianas. Esse descanso no tempo livre é muitas vezes representado através da idéia de "não fazer nada", ou com a frase que freqüentemente foi citada nos grupos focais: "Quando a gente tá de 'bobeira' em casa e não tem nada para fazer." (E4- grupo 12 a 14 anos).

Pretendemos, a seguir, realizar uma análise acerca dos significados do tempo livre a partir da integração das três categorias emergentes. Dessa forma, abordaremos o tempo livre não só destacando a noção de liberdade mas também agregando-lhe a característica de um sentimento de satisfação e prazer mediante momentos e atividades que propiciem descanso, desenvolvimento e/ou diversão.

\section{Discussão}

Os adolescentes pesquisados foram capazes de dar significados ao seu tempo livre, sendo que algumas vezes agem de acordo com esses significados, outras vezes não. Assim, o uso do tempo livre desses adolescentes nem sempre esteve em consonância com suas crenças, percepções e significados, pois aquilo que eles pensavam e afirmavam ser o tempo livre muitas vezes se diferenciou dos seus comportamentos e de suas atitudes diante desse tempo.

Essas contradições nos levaram a compreender o significado do tempo livre, na perspectiva dos adolescentes, como uma temática complexa, como um tempo no qual as atividades desenvolvidas podem ser sentidas de forma 
diferente, ter funções distintas e despertar sentimentos contraditórios de indivíduo para indivíduo. É importante mencionar que o significado e o uso do tempo livre se entrelaçam, se complementam e abarcam contradições, conforme a análise dessa temática sob a ótica da complexidade (Munné, 1985; Morin e Moigne, 2000; Morin, 2001, 1993).

Os participantes da pesquisa, por atribuírem significado ao tempo livre a partir da liberdade de escolha inerente a esse momento, consideraram que as atividades obrigatórias não são percebidas como tempo livre justamente por serem contrárias à noção de liberdade ou autonomia. Para os adolescentes pesquisados, as atividades escolares assumem esse caráter de obrigação.

A escola, sendo uma instituição que apresenta certos condicionantes, tais como relação assimétrica entre professor e aluno, plano pedagógico pré-determinado e exigência legal e social de freqüência, remete à noção de heterocondicionamento (Munné, 1985). É válido esclarecer que, partindo de uma perspectiva psicossocial crítica, deveria haver no tempo livre o predomínio do autocondicionamento sobre o heterocondicionamento, visto que o tempo livre pressupõe a auto-realização e a liberdade de escolha como condicionantes (Munné, 1985). Essas instâncias, entretanto, não operam de forma antagônica (quanto maior uma, menor a outra), mas sim, de forma "borrosa" (ambas podem ser elevadas ou ambas baixas).

Segundo Casas e Codina (1998), toda atividade autocondicionada de tempo livre promove a capacidade de auto-organização do indivíduo. Em paralelo, essas atividades também podem adquirir variáveis heterocondicionantes, como os recursos disponíveis, o estímulo e o direcionamento do contexto externo. Cabe ressaltar ainda que essa perda de autonomia imposta pela obrigatoriedade das atividades escolares é relativa, pois no espaço escolar também é possível intervir, sugerir, indagar e se colocar de muitas formas diferentes.
Geralmente, é através do recreio que a escola dá aos alunos oportunidade de desfrutar momentos lúdicos, de diversão e de descanso. A importância desse momento, no qual há o desenvolvimento, por parte do adolescente, de atividades com pouca orientação dos adultos, é a possibilidade para que se estabeleça a livre expressão da criatividade desses jovens (Puig e Trilla, 2000).

Na passagem da infância para o início da adolescência, o padrão de influência de atividades de tempo livre não sofre grandes alterações, já que os pais e a escola seguem direcionando as tarefas cotidianas (Kleiber, 1999) e mantendo, principalmente, as condições de heterocondicionamento. Ao analisar o conteúdo das verbalizações dos dois grupos etários pesquisados, foi observado que as atividades de tempo livre dos adolescentes de 12 a 14 anos são gerenciadas pelos pais e educadores de forma mais intensa e freqüente do que ocorre com os adolescentes de 15 a 18 anos. Dessa forma, conforme aumenta a faixa etária, a possibilidade de autonomia em relação às atividades de tempo livre se torna mais presente em variados graus.

Por outro lado, o tempo livre dos adolescentes mais velhos que estudam e trabalham se torna mais escasso. Ao focalizar os adolescentes de 15 a 18 anos que possuem emprego, percebese que o tempo destinado às atividades de tempo livre se reduz em função da jornada de trabalho. Mesmo possuindo maior autonomia, o fato de estarem ocupados durante todo o dia da semana com as atividades escolares e laborais acaba por reduzir a possibilidade de aproveitar o tempo livre com maior liberdade de escolha. Esses jovens trabalhadores buscam compensar no fim de semana o desgaste da semana - alguns com diversão e abusos, outros com descanso. Assim, conforme Munné (1985), os momentos em que não estão estudando ou trabalhando são vistos mais como um tempo liberado de (escola e trabalho) do que um tempo livre para.

Verificamos que ambos os grupos etários pesquisados afirmam sentir prazer e satisfação 
na presença do grupo de amigos, tendo a atividade realizada uma importância secundária. De acordo com Codina (1999, 2002), a socialização no tempo livre estimula a autorealização do indivíduo, a qual influencia o modo como o adolescente se percebe e conhece suas capacidades e limitações, para assim saber agir de uma forma mais saudável, integrada e madura no seu dia a dia. O tempo livre vivenciado junto aos amigos proporciona o estabelecimento de relações nas quais elaboram e compartilham visões de mundo, negociam significados, criam cumplicidades com os diversos grupos de amigos, desenvolvem maior independência emocional e se envolvem mais com questões do seu contexto social (Zamora et al, 1995; Franch, 2002; Câmara, 2003).

Conforme mencionado pelos adolescentes pesquisados, entretanto, o fato de darem mais importância a estar com os amigos no seu tempo livre do que à estruturação da atividade a ser realizada, a socialização desses adolescentes pode tornar-se um elemento propiciador de maior vulnerabilidade. O convívio com os pares é algo prazeroso e vai ao encontro do bemestar e da qualidade de vida, mas é justamente nesse espaço de interação que se apresenta uma variável de risco: o álcool e as drogas ilícitas. A experimentação e a continuidade do uso dessas substâncias foram associadas, por alguns dos participantes, ao grupo de amigos.

Mesmo que o consumo de álcool, por exemplo, seja expressamente proibido para menores de 18 anos, Pechansky, Szobot e Scivoleto (2004) apotaram que o uso dessa substância pelos adolescentes se evidencia nos mais diferentes âmbitos, desde festas familiares até locais públicos. Os autores chamam a atenção para o fato de que, para se diagnosticar o uso, o abuso ou a dependência de álcool nessa faixa etária, deve-se ter conhecimento sobre as particularidades da dependência química nessa etapa da vida. A American Academy of Pediatrics, conforme apontam esses autores, sustenta que a experimentação de drogas, dentro de certos padrões, pode inclusive ser vista como uma conduta normal nesse período de desenvolvimento, embora se saiba que, quanto mais precoce o uso, maior o risco de surgirem conseqüências graves (orgânicas, cognitivas, psicológicas, sociais). Como não foi feita nenhuma investigação aprofundada sobre hábitos de consumo de álcool junto aos adolescentes pesquisados, não pode se afirmar se a referência ao álcool feita pelos participantes se aproxima mais da experimentaçao ou do abuso dessa substância.

Estar com amigos, e, nessas situações, fazer uso de álcool ou drogas, representa uma complexa relação entre bem-estar e comportamento de risco, conforme afirmou um adolescente: "Ou tu leva junto, ou te levam junto, entendeu.” (E4grupo 12 a 14 anos). Em outras palavras, devese considerar que a convivência nos grupos pode ser o ponto de partida efetivo para alguns comportamentos de risco, como o consumo precoce de substâncias psicoativas (Pechansky, Barros, 1995, citado por Pechansky, Szobot, Scivoletto, 2004).

Apesar dos riscos mencionados, as aprendizagens, conhecimentos e atividades advindas da interação social contribuem para que, nas situações de envolvimento com atividades individuais, o adolescente tenha mais uma oportunidade de crescimento. O grupo de 15 a 18 anos descreveu maior número de atividades individuais satisfatórias realizadas por livre escolha no seu tempo livre, o que demonstra maior compreensão e apropriação de seus processos sociais e psíquicos (Zamora et al., 1995).

Mesmo assim, observamos uma dificuldade dos adolescentes de expressarem o que realmente gostam de fazer, já que citaram diversas atividades desvinculadas de uma crítica a respeito e de sentimentos por elas. Talvez essa dificuldade seja decorrente do não planejamento do tempo livre e da falta recursos materiais financeiros e ambientais, o que é percebido principalmente pela presença de momentos de ociosidade e falta de produtividade física e mental, em especial no grupo de 12 a 14 anos. 
As verbalizações dos adolescentes revelam, ainda, que o significado do tempo livre está relacionado com a dimensão temporal, já que os finais de semana e as férias são descritos como momentos vivenciados com muita satisfação, em virtude da maior disponibilidade de tempo e de autonomia para escolher suas atividades; assim, afirmam que é possível aproveitar ao máximo seu tempo livre executando atividades cuja realização se torna inviável durante a semana e o ano letivo.

O ócio é entendido como uma maneira de se comportar no tempo (Codina, 2002), e equivale ao tempo livre quando há expressão de liberdade enquanto seres humanos, quando as atividades correspondem a um comportamento autocondicionado (Munné, 1985); dito de outra forma, quando há liberdade de escolha e prazer mediante a realização da atividade escolhida. $\mathrm{O}$ que torna o ócio terapêutico para o indivíduo é a utilização desse tempo como uma possibilidade de reflexão sobre suas práticas de vida, que reforça a idéia de que todo ser humano necessita de um tempo para si, podendo este ser desfrutado livremente, sem obrigações e compromissos.

Ainda que o jovem nem sempre perceba, a atividade de tempo livre cumpre uma função em sua vida, seja ela de socialização, de descanso, de organização interna de pensamentos, emoções, aprendizados, etc. A função que determinada atividade cumpre só pode ser analisada e compreendida a partir do significado que o jovem lhe atribui, e mesmo que a sensação preponderante seja o desconforto (no caso de uma atividade imposta), o significado pode ser positivo (sabe que é necessário, importante para a aprendizagem).

O significado do tempo livre como momento para compensar o cansaço das atividades escolares obrigatórias é entendido como um meio para a recuperação da fadiga, no qual o adolescente dispõe de maior liberdade de tempo para satisfazer desejos e necessidades pessoais, que são frustrados no cotidiano (Codina, 2002). O descanso físico e mental advindo desse momento de compensação pode, dependendo de sua freqüência e da escassez de atividades de tempo livre, adquirir o caráter de tédio, de ociosidade: "Quando não tem nada pra fazer, ah, eu não gosto" (sic).

Nos momentos em que o adolescente não realiza alguma atividade e está entediado, não aprende e se desenvolve, não produz algo novo, não experimenta nem escolhe novas situações. Dessa forma, o tempo livre pode ser sentido como um tempo perdido, sem significado. $\mathrm{O}$ ócio para o descanso, então, assume uma característica de ambigüidade, visto que cumpre tanto a função de compensação como também a de tédio.

O ócio para o descanso, na perspectiva dos participantes, também está relacionado ao uso de drogas ilícitas. Ao dar significado ao tempo livre como um tempo para o descanso, alguns adolescentes apontaram essa possibilidade: " $E$ que o cara não tem nada para fazer, não tá ocupado com nada, fica lá quieto pensando, bah, o que que eu podia fazer? Bah, vou 'fumar um beck'”. (E4 -grupo 12 a 14 anos). Assim, a percepção do jovem de não ter nenhuma atividade a desenvolver pode levá-lo a comportamentos no seu tempo livre que implicam riscos ao seu desenvolvimento físico e emocional, fato reconhecido inclusive pelos próprios adolescentes, quando afirmaram "O cara se acaba sozinho" ou "Fica seqüela se tu fuma direto, e depois isso fica pro resto da tua vida." (E4 - grupo 12 a 14 anos).

Dentre as escolas pesquisadas, nem sempre aquelas com melhores condições de infraestrutura ofereciam atividades extraclasse. Às vezes, aquelas com escassos recursos, porém com melhor organização favoreciam o desenvolvimento dos adolescentes através de atividades que resultassem em diversão após o horário escolar. O ócio que proporciona diversão e desenvolvimento é entendido como um ócio positivo para a personalidade dos participantes, uma vez que, de acordo com Codina (2002), este melhora a auto-imagem, produz sentimentos de realização, cria laços sociais e sentimento de pertença, levando à autoatualização, auto-enriquecimento e autoexpressão. Os adolescentes citaram, ainda, classificadas nesse tipo de ócio, as atividades 
relacionadas à formação, que objetivam a aprendizagem pessoal. Exemplos disso são os cursos de idiomas e grupos de estudos. No entanto, na mesma ordem da complexidade, uma mesma atividade oferecida pela escola aos adolescentes pode ser classificada como algo que proporciona diversão: "Pra mim a capoeira é um tempo livre, é mais pra descontrair” (sic), ou não: "Capoeira e teatro é uma coisa que eu considero como um compromisso" (sic), sendo vista e experienciada de formas diferentes.

\section{Conclusões}

Constatamos que o tempo livre perpassa pelas questões individuais, porém não podemos deixar de contemplá-lo de acordo com o contexto sociocultural no qual o adolescente está inserido. Da mesma forma, verificamos a importância dos recursos ambientais, na medida em que a comunidade forneça uma infra-estrutura que facilite o acesso de jovens de classe popular a atividades saudáveis no tempo livre. Acreditamos que esse item deveria ser priorizado nas diretrizes das políticas públicas vigentes, já que pesquisas apontam a falta de equipamentos públicos ou comunitários que propiciem o direito ao esporte, cultura e lazer gratuitos aos jovens de classe popular (UNICEF, 2002), visto que os adolescentes de classes mais favorecidas naturalmente têm acesso a clubes, escolas artísticas e culturais, etc.

Ao investigarmos essa temática, e baseados nos significados que os próprios adolescentes atribuem ao seu tempo livre, é possível pensarmos que, mesmo diante de carências financeiras e de investimento social, os adolescentes sabem organizar seu tempo livre destacando, sobretudo, a interação social que o tempo livre promove nesse grupo pesquisado. Porém também existe um considerável tempo livre que por falta de conhecimentos, por pouca clareza nas metas vitais, por pressões grupais e por falta de oportunidades poderia ter outra configuração em termos de auto-realização e satisfação vital, sem ter que se recorrer ao exercício da liberdade, à satisfação do desejo e à afirmação pessoal através da exposição a situações de risco.

Jorge Castellá Sarriera

Doutor em Psicologia, Mestre em Psicologia Escolar, pesquisador do CNPq e membro do CA, (CNPq), professor adjunto da UFRGS, coordenador do Grupo de Pesquisa em Psicologia Comunitária desde 1993.

Luciana Fernandes Marques

Doutora em Psicologia, membro do Grupo de Pesquisa em Psicologia Comunitária.

\section{Ângela Carina Paradiso}

Psicóloga, mestranda do Programa de Pós-Graduação em Psicologia da UFRGS, membro do Grupo de Pesquisa em Psicologia Comunitária.

Júlia Schneider Hermel

bolsista de Iniciação Científica da FAPERGS, membro do Grupo de Pesquisa em Psicologia Comunitária e graduanda do $9^{\circ}$ semestre da Faculdade de Psicologia da PUCRS.

\section{Paula Nunes Mousquer}

Bolsista CNPq-PIBIC, membro do Grupo de Pesquisa em Psicologia Comunitária e graduanda do $6^{\circ}$ semestre da Faculdade de Psicologia da PUCRS.

Roberta P. Schell Coelho

Bolsista de Iniciação Científica do CNPq, membro do Grupo de Pesquisa em Psicologia Comunitária e graduanda do $9^{\circ}$ semestre da Faculdade de Psicologia da PUCRS.

Rua Álvares Machado, 120, ap. 502 - Porto Alegre RS - 90630-010. E-mail: sarriera@terra.com.br 
ASSIS, S.G. PESCE, R P• AVANCI, J.Q Resiliência: enfatizando a proteção dos adolescentes. Porto Alegre:Artemed. 2006.

ARGYLE, M. Psicología y calidad de vida. Intervención Psicosocial Madrid, v. 3, n. 6, p. 5-16, 1993.

BATTRAM, A. Navegar por la complexidad: guia básica sobre la complexidad en la empresa e la gestión. Barcelona: Granica, 1999.

CÂMARA, S. G. Comportamentos de risco na adolescência: enfrentamento violento, conduta sexual de risco e consumo de drogas ilegais. Tese de doutorado em Psicologia, Pontifícia Universidade Católica do Rio Grande do Sul, Porto Alegre, 2003.

CASAS, F.; CODINA, N. Infancia, adolescencia y ocio: una experiencia comunitaria afrontando la exclusión social. In: A. MARTÍN (Ed.), Psicología comunitaria: fundamentos y aplicaciones. Madrid: Sínteses, 1998.

CASTRO, M.; ABRAMOVAY, M. Jovens em situação de pobreza, vulnerabilidades sociais e violências. Casos em áreas urbanas, Brasil, 2002. In: ABRAMOVAY, M. Escola e Violência. Brasília: UNESCO, UCB, p.17-56, 2003.

CODINA, N. Los desportes de aventura como "ocio serio" y su impacto en la calidad de vida. Trabalho apresentado no VII Congresso Nacional de Psicología de la Actividad Fisica y el Desporte, Murcia, v. 2, p. 166-172, 1999.

El ocio en sistema complejo del self. In: CAVA, M. J. (Ed.) Propuestas alternativas de investigación sobre ocio. Documentos de estudios de ocio, 20. Bilbao: Universidad de Deusto. Instituto de Estudios de Ocio, p.57-72, 2002.

Una aproximación a la complejidad del tiempo libre y del self mediante la aplicación cualitativa secuencial de los presupuestos del tiempo. Encuentros en Psicología Social, Málaga, v. 2, n. 1, p. 332-340, 2004.

CUNHA, N. A felicidade imaginada. São Paulo: Brasiliense, 1987.

DUMAZEDIER, J. Lazer e cultura popular. São Paulo: Perspectiva, 1973.

FERNÁNDEZ, A. R.; MARTÍN, V. Z.; MUÑOZ, C. A. Cuestiones conceptuales y metodológicas en torno del concepto y significado de bienestar social. Intervención Psicosocial, Madrid, v. 3, n. 6, p. 17-28, 1993

FRANCH, M. Nada para fazer? Um estudo sobre atividades no tempo livre entre jovens de periferia no Recife. Revista Brasileira de Estudos de População, São Paulo, v.19, n.2, p. 117-132, 2002

GORAYEB, R. Conhecimentos, atitudes e comportamentos de estudantes de $1^{\circ} \mathrm{e} 2^{\circ}$ graus de Ribeirão Preto sobre fatores de risco à saúde. Tese de doutorado em Medicina, Universidade de São Paulo, Ribeirão Preto, 1990.

KLEIBER, Douglas A. Leisure experience and human development. New York: Basic Books, 1999.

MORIN, E. Ciência com consciência. Rio de Janeiro: Bertrand Brasil, 2001.

MORIN, E.; MOIGNE, J. A inteligência da complexidade. São Paulo: Peirópolis, 2000.

MORIN, E. Epistemologia da complexidade. In: FRIED, D. (Org.). Novo paradigmas, cultura e subjetividade. Porto Alegre: Artes Médicas, 1996.

Contrabandista de saberes. In: PESSIS-PASTERNAK, G. Do caos à inteligência artificial, quando os cientistas se interrogam. São Paulo: Editora da Universidade Estadual Paulista, 1993.

MUNNÉ, F. Psicosociología del tiempo libre: un enfoque critico. México: Ed. Trillas, 1985.

MUNNÉ, F.; CODINA, N. Ocio e tempo livre: consideraciones desde una perspectiva psicosocial. Revista Licere, Belo Horizonte, v. 5, p. 59-72, 2002.

Psicología social del ocio y el tempo livre. In: ÁLVARO, J.; A. GARRIDO; J. TORREGROSA(Orgs.), Psicologia social aplicada. Madrid: Mc Graw-Hill, 1996.

PECHANSKY, F., SZOBOT, C. M.; SCIVOLETTO, S. Uso de álcool entre adolescentes: conceitos, características epidemiológicas e fatores etiopatogênicos. Revista Brasileira de Psiquiatria, São Paulo, v. 26 (Supl.), p.14-17, 2004

PUIG, J. M.; TRILLA, J. La pedagogía del ocio. Barcelona: Editorial Alertes, 2000.

SCHNITMAN, D. F. (Org.) Nuevos paradigmas, cultura y subjetividad. Buenos Aires: Paidós, 1995

TANAKA, O. Y. Avaliação de programas de saúde do adolescente: um modo de fazer. São Paulo:Edusp, 2001.

UNICEF. (2002). Avoz do adolescente [On-line] Disponível: http: / /www.unicef.br.

ZAMORA, R.; TOLEDO, M.; SANTI, P.; MARTINEZ, M. El tiempo libre y la recreación: estudio en adolescentes uruguayos. In: ZAMORA R.; TOLEDO, M.; SANTI, P.; MARTINEZ, M. La salud del adolescente y del jóven. Washington: Matilde Madaleno, 1995. p. 533-544.
Referências 